\title{
Entrevista com Elizabeth Tunes
}

\author{
Ingrid Lilian Fuhr' \\ Darliane Silva do Amaral" \\ Aline de Souza Pereira"l' (D)
}

\section{APRESENTAÇÃO}

Entre os pesquisadores que se dedicam ao estudo da obra de Lev Semionovitch Vigotski e suas implicações para o cenário atual da psicologia e da educação, destaca-se a professora doutora Elizabeth Tunes, pioneira no Brasil a respeito dos estudos realizados pelo precursor da teoria histórico-cultural. Elizabeth Tunes é responsável por trazer os estudos de Vigotski para a Universidade de Brasília $(\mathrm{UnB})$. Desde os anos iniciais da década de 1980, realiza um trabalho incansável para a formação de pesquisadores nessa abordagem teórica, dedicando-se à defesa de uma educação emancipadora e não excludente. No ano de 1996, criou o Grupo de Pesquisa e Consultoria Escolar (GruPesColar), uma sociedade civil sem fins lucrativos estruturada para o desenvolvimento de estudos e pesquisas sobre questões relativas à escola e ao processo de escolarização. O GruPesColar, até o final da década de 1990, desenvolvia atividades de assessoria a pedagogos e psicólogos escolares no seu trabalho de diagnóstico e acompanhamento de crianças e jovens com deficiência ou com problemas no processo de escolarização; atendimento a professores do ensino regular, especialmente com vistas à identificação, análise e dimensionamento de problemas de ensino, bem como encaminhamento de soluções; atendimento psicopedagógico de crianças e jovens com deficiência ou com problemas no processo de escolarização; observação, acompanhamento e supervisão do trabalho de professores, pedagogos e psicólogos escolares; elaboração de material 
didático para o ensino dessas crianças ou jovens, bem como para profissionais que atuam na escola; entre outras ações.

Elizabeth Tunes possui graduação em psicologia pela UnB, mestrado e doutorado em psicologia pela Universidade de São Paulo (USP) e pós-doutorado pelo Centro de Desenvolvimento Sustentável (CDS) da UnB. Em sua carreira acadêmica, concentrou-se em investigar o desenvolvimento psicológico atípico e a deficiência mental - termo usado na época para deficiência intelectual -, o significado social da escola, os processos de escolarização, o conhecimento científico e o conhecimento escolar, bem como as relações entre ensino e desenvolvimento. Empenha-se na investigação das bases filosóficas que amparam a teoria de Vigotski, que em muito contribui para compreender o pensamento desse teórico. Atualmente, dedica-se, em parceria com a professora doutora Zoia Prestes, à tradução para o português de algumas obras inéditas de Vigotski, como 7 Aulas de L. S. Vigotski, e de outras já publicadas, como Imaginação e criação na infância.

Diante de sua história acadêmica e de sua relevante contribuição para a educação, principalmente para o ensino especial, realizamos a presente entrevista, por considerarmos que ela irá subsidiar profissionais que atuam nas áreas de educação e psicologia e em futuras reflexões sobre a teoria histórico-cultural de Vigostki.

Lev Semionovitch Vigotski nasceu em 17 de novembro de 1896, em Orsha, uma pequena cidade da Bielorrússia. Seus postulados teóricos foram elaborados no contexto turbulento dos anos em que ocorreu a Revolução Russa. Sua formação acadêmica deu-se em direito e medicina, com estudos na área de literatura, história e artes. As investigações de Vigotski foram dedicadas principalmente ao desenvolvimento cultural, em especial da criança. Fundamentado nas proposições teóricas do materialismo histórico de Karl Marx e na filosofia de Spinoza, formulou um sistema teórico conhecido hoje como teoria histórico-cultural do desenvolvimento da criança.

Entre suas muitas realizações, fundou a Escola Soviética de Psicologia Histórico-Cultural, realizando pesquisas do maior interesse para a psicologia e a educação, que incluem, entre outros, o desenvolvimento de crianças acometidas por um defeito congênito ou adquirido, apontando para a possibilidade de as crianças se desenvolverem mediante caminhos alternativos. Em sua ampla trajetória profissional está a direção do Departamento de Educação do Instituto de Deficiências de Moscou. Sua obra abrange estudos na área da literatura, das artes, da psicologia e da educação. Mesmo sua vida tendo sido interrompida pela tuberculose, em 1934, aos 37 anos, Vigotski deixou uma vasta produção que em sua grande parte permanece sem tradução ou até mesmo publicação.

\section{ENTREVISTA COM ELIZABETH TUNES}

\section{Professora Elizabeth Tunes, como se deu seu primeiro encontro com a obra de Vigotski? \\ Isso aconteceu quando eu estava para concluir meu doutorado, no início de 1980. No meu trabalho, eu me dedicava a examinar a importante questão dos relatos verbais a respeito de processos psicológicos. Trata-se de uma questão de}


método muito importante de se examinar no âmbito da psicologia. Isso surgiu pelo meu interesse em compreender por que alguns estudantes de pós-graduação, meus colegas, afirmavam sentir dificuldade para elaborar seus projetos de pesquisa. Esse fato me intrigava! Por que eles sentiam dificuldade para definir um problema para investigar e qual era essa dificuldade? Afinal, o campo da psicologia apresenta tantos problemas de grande interesse para a investigação que essa situação tornava-se muito intrigante. Assim, resolvi investigar essa questão. Mas eu só poderia investigá-la se conversasse com os estudantes que manifestavam tal dificuldade. Então comecei a estudar sobre o relato verbal e sua validade como informação científica a respeito de processos psicológicos. Na época, no Departamento de Psicologia Experimental da Universidade de São Paulo, o professor Arno Engelmann ministrava aulas na pós-graduação. Eu o admirava muito, tanto pela profundidade do seu conhecimento quanto pela delicadeza da pessoa que ele era. Era um grande pesquisador, dedicava-se com profundidade ao que fazia, um excelente professor. Eu não perdia nenhuma disciplina que ele ministrava. Aprendi muito com ele sobre o problema metodológico do uso de relatos verbais no estudo de processos psicológicos. Aliado a isso, havia o fato de que eu tinha uma formação muito forte em análise experimental do comportamento. À época, já havia estudado boa parte da obra de Burrhus Frederic Skinner, inclusive seu livro Verbal behavior, que me interessava muito por permitir a reflexão sobre inúmeras questões importantes sobre o falar humano. Ao atender às aulas do professor Arno, pude desenvolver uma crítica metodológica à abordagem skinneriana. Ao mesmo tempo, minha orientadora, a professora Carolina Bori, elaborava trabalhos de investigação sobre questões ligadas ao ensino e, à época, estava bastante interessada em examinar como os professores pensavam sobre essas questões. Para isso, ela vinha desenvolvendo uma metodologia e um procedimento de trabalho com os relatos verbais dos professores e as possibilidades de inferências que permitiam sobre seus modos de pensar. Unindo Arno Engelmann com Carolina Bori, foi possível definir e realizar uma proposta para o meu doutorado.

No último ano de meu doutorado, eu me encontrava na sala da minha orientadora para receber suas orientações, mas ela precisou retirar-se por um momento e, enquanto esperava, comecei a olhar seus livros na estante. Naquele momento, estava ansiosa por encontrar material que me ajudasse principalmente na interpretação dos meus resultados. Encontrei um livro com o título Thought and language. Eu o retirei da estante, folheei-o e verifiquei que era de um autor russo, Vigotski, traduzido para o inglês. Naquele momento, pensei que poderia ser interessante para o que eu fazia, uma vez que tratava, a meu ver, da interface pensamento e linguagem. Tomei-o emprestado, fiz uma cópia xerox, à época uma ação muito comum entre estudantes e professores. Comecei a estudá-lo e constatei que o assunto tratado casava-se perfeitamente com o que eu fazia. Contudo, percebi também que o tratamento era de grande complexidade e que eu precisaria conhecer um pouco mais o autor, ler outras obras suas, saber quem era etc., e eu não dispunha mais de tempo para isso. $\mathrm{O}$ prazo para minha defesa de doutorado se esgotaria ao final daquele ano; em menos de um ano eu não conseguiria realizar tudo isso, além de concluir a análise e interpretação dos resultados que obtive, bem como a redação da tese. De qualquer modo, li o livro até o fim e o deixei na espera para uma releitura quando 
concluísse o doutorado. Assim que isso aconteceu, retornei a ele e pude, com tristeza, verificar que, se eu tivesse tido acesso ao autor pelo menos um ano antes, meu trabalho final teria sido diferente.

Daí em diante, dediquei-me com afinco ao estudo das obras de Vigotski e de outros autores de sua escola. Visitava constantemente as livrarias, procurando por outras obras suas - naquele tempo, não havia Google, tampouco obras disponíveis na internet. Logo de início, encontrei uma coletânea de Alexandre Luria e uma ou outra publicação aqui e ali. Li e reli as poucas obras que até então pude encontrar. E, assim, comecei a estudar e me aprofundar na teoria histórico-cultural de Vigotski. Fiz um grupo de estudos com colegas que se interessaram e começamos a realizar leituras e debates coletivos. Curiosamente, no mesmo momento em que chegou a mim, chegou também a outras pessoas. Por exemplo, na Universidade Estadual de Campinas, alguns professores começaram a estudar Vigotski com o professor Angel Pino. Na Universidade Federal de São Carlos, à qual eu pertencia, a professora Maria Cecília Góes havia retornado da Inglaterra, e ela também ouvira falar de Vigotski e estava interessada em estudá-lo. Pude, assim, perceber que o meu movimento em relação a Vigotski também estava acontecendo com outras pessoas.

Naquele tempo, eu realizava alguns projetos com professores de química da Universidade Federal de São Carlos, buscando melhorar o ensino de ciências. Resolvi propor a eles que tentássemos aplicar ideias de Vigotski à análise que fazíamos do ensino de química. Como sabemos, o ensino de química sempre apresentou muitos problemas. Em geral, até hoje, os alunos reclamam muito. Propus, assim, que verificássemos se Vigotski poderia ajudar-nos a compreender aqueles problemas e começamos a realizar a leitura e discussão do livro Pensamento e linguagem, aplicando as ideias ao ensino de química. Compusemos esse grupo de estudos e começamos a fazer a análise de conceitos de química à luz do pensamento de Vigotski.Iniciamos pela tentativa de identificar sistemas conceituais que poderiam ser compostos com os conceitos de química e a compará-los com os modos como eram ensinados tanto na universidade quanto no ensino médio. Faziam parte do nosso grupo dois professores com experiência no ensino médio. Um deles era o professor Mário Tolentino. Ele era autodidata e tornara-se professor da Universidade Federal de São Carlos por notório saber. Além dele, participavam do grupo os professores Romeu Cardozo Rocha Filho e Roberto Ribeiro da Silva, ambos também da Universidade Federal de São Carlos, e o professor Emílio Carlos Poderoso de Sousa, que trabalhava na Secretaria Estadual de Educação do Estado de São Paulo. Começamos a delinear os sistemas conceituais e a compará-los com os que se empregavam nos livros didáticos e pudemos, então, constatar que de fato o ensino de química poderia ser organizado de um modo diferente, que pudesse contribuir com mais eficiência para tornar possível o desenvolvimento do raciocínio dos estudantes. Isso aconteceu no decorrer da década de 1980 e, a partir daí, continuei dedicando-me ao estudo e aprofundamento da teoria histórico-cultural.

Ao final do ano de 1988, mudei-me para Brasília e tornei-me professora do Instituto de Psicologia da Universidade de Brasília. Eu ministrava uma disciplina com o exótico nome de psicologia do excepcional, herança dos tempos em que ainda era aluna do curso de psicologia, na Universidade de Brasília. Os tempos 
mudaram, mas o nome da disciplina permaneceu o mesmo ao longo de vinte anos. Chegou às minhas mãos a versão preliminar da obra Fundamentals of defectology, que iria ser publicado em inglês. $\mathrm{Na}$ disciplina que eu ministrava, é claro, dedicava um bom tempo ao exame do conceito de deficiência e da problemática envolvendo a deficiência mental. Baseada nos estudos da análise do comportamento, eu entendia que esse conceito, do ponto de vista científico, era muito problemático, por definir-se como uma negação - a deficiência é a ausência de algo - e por ser empregado, na maioria das vezes, como um construto hipotético com poder de explicação causal do comportamento. Ou seja, há uma inversão: o que deveria ser explicado pela teoria - a deficiência - torna-se o fator explicativo. Quando tive acesso à primeira versão, ainda sem revisão, daquela coletânea de textos de Vigotski, passei a estudá-la e usá-la como obra de referência na disciplina que eu ministrava. Pouco tempo depois, foi publicado o volume nos Estados Unidos e tive a oportunidade de adquiri-lo. $\mathrm{O}$ acesso a essa obra foi um enorme presente, porque possibilitava reflexões bastante aprofundadas sobre o conceito de deficiência, permitindo críticas importantes aos modos como a psicologia e a educação, de maneira geral, operavam e operam com esse conceito. Vigotski, de fato, apresenta um corpo teórico coerente, fundamentado, que me permitia continuar minha busca de entendimento do conceito de deficiência. Vale esclarecer que, à época, minha maior preocupação era com o conceito de deficiência mental, definida como "ausência de inteligência". Do ponto de vista científico, esse conceito me parece mais uma aberração lógica que um conceito científico, propriamente falando. Até os dias de hoje, ocupo-me do estudo do desenvolvimento da criança com deficiência, embasada em ideias e formulações de Vigotski e de outros autores que têm os mesmos fundamentos ético-filosóficos que ele.

Então, foi assim que comecei. E até hoje me encontro nessa linha de estudo dos fenômenos psíquicos.

\section{Professora, em um primeiro olhar, o que Vigotski despertou em você?}

A primeira coisa que me despertou foi muita admiração e muita satisfação. Afinal, eu havia encontrado um teórico que respondia... $\mathrm{Na}$ verdade, não respondia, porque Vigotski não responde a questões, apenas nos orienta teoricamente para saber quais questões que devem ser formuladas. Foi, portanto, uma grande satisfação e uma enorme admiração pela maneira como construiu sua teoria, pelos seus fundamentos filosóficos e éticos, pela sua genialidade. A sua abordagem, enfim, correspondia a uma série de buscas que havia muito tempo eu fazia na psicologia, de um modo geral. Por exemplo, a questão da transposição de princípios e leis que explicam o comportamento animal, diretamente para processos humanos. Não consigo aceitar que essa seja uma generalização possível ou, pelo menos, feita com tanta agilidade assim, porque há uma diferença enorme entre a vida humana e a vida animal. Não acho possível aceitar que princípios de psicologia que se apliquem a processos elementares sejam estendidos à compreensão de processos altamente complexos, como é o caso da fala humana. A fala humana é altamente complexa e muito distinta de tudo o que ocorre com os animais. Ainda que já se tenham feito 
muitos avanços na sua compreensão, estamos ainda muito longe de poder dizer que esgotamos o seu entendimento.

Fiquei muito empolgada porque Vigotski me trazia uma nova perspectiva para a psicologia. Eu sempre tive muita relutância em aceitar as visões naturalistas no âmbito da psicologia. Isso se deveu exatamente à minha formação em análise experimental do comportamento. A análise experimental do comportamento me trouxe essa inquietação e eu ansiava muito por abordagens que ultrapassassem a visão biológica do psiquismo humano. Vigotski é muito importante para a psicologia, é muito importante para mim. Ao encontrá-lo, eu me encontrei em suas páginas.

\section{Professora Elizabeth, à luz dos seus estudos sobre a teoria histó- rico-cultural de Vigotski, qual a reflexão que você faz a respeito da psicologia e da educação no Brasil?}

Essa pergunta é bastante complexa e diz respeito não somente ao Brasil, mas a todo o mundo ocidental. A obra de Vigotski já tem pouco mais de cem anos. Ele escreveu sua primeira monografia sobre Hamlet, portanto, ligada ao campo da arte, entre 1915 e 1916 . O sistema teórico que ele criou trouxe uma perspectiva revolucionária para o mundo, e não apenas para a União Soviética. Lá também imperava o biologicismo na psicologia. Vigotski formou uma escola com bastante influência, que teve muita repercussão, mas também foi demasiadamente recalcada e proibida pelo regime. Na própria União Soviética, suas proposições não chegaram a produzir transformações importantes na educação. Não houve qualquer impacto digno de nota no campo da educação, salvo algumas iniciativas pontuais, entre as quais se pode citar a chamada Escola de Zagorsk, que ainda existe na cidade de Sergueiev Possad, antiga Zagorsk, próxima a Moscou. O Instituto de Defectologia, no qual ele trabalhou, fez muitas coisas, mas que também não tiveram grande impacto.

A educação no Brasil tem características que não a fazem muito diferente, em essência, da educação que ocorre no mundo. Nos Estados Unidos, por exemplo, especialmente no campo do ensino de ciências, não se tem notícia de qualquer revolução ou mudança significativa tornada possível por influência da teoria histórico-cultural. Ela poderia promover uma revolução na educação? Por si só, é claro que não, pois uma revolução não se produz em virtude de uma teoria. Mas ela poderia trazer movimentos importantes que pudessem gerar novas formas de conceber a educação de crianças e jovens no mundo. É claro que a teoria em si não prescreve uma forma de agir educacional. A teoria não é prescritiva da ação, mas poderia, se bem cultivada e bem desenvolvida, ter gerado movimentos e conhecimentos que permitissem um avanço significativo no campo da organização da educação.

Do meu ponto de vista, a teoria de Vigotski não foi ainda examinada com a profundidade devida em relação às suas implicações no campo educacional. Há uma carência absoluta de estudos e trabalhos empíricos e teóricos acerca do fenômeno educativo à luz da teoria. Não estou me referindo à aplicação da teoria na educação - isso não faz sentido e não é a proposta de Vigotski. Essa me parece ser uma visão um pouco equivocada do senso comum de que a teoria científica existe para ser aplicada na prática. Não é bem assim. Na verdade, a teoria orienta nossa reflexão sobre o fazer e é dessa reflexão que poderão surgir propostas e formas 
criativas, inovadoras no campo da educação. Contudo, essas formas são criadas pelos educadores e não prescritas pela teoria. Os modos de agir podem ser - e muitas vezes são - orientados pela teoria, mas não ditados por ela. Assim, o que estou dizendo é que, do meu ponto de vista, esses modos de agir no campo da educação, inspirados pela teoria, não foram criados nem na União Soviética nem em lugar algum do mundo.

Nos dias de hoje, tanto nos países ocidentais quanto na Rússia, as políticas educacionais são muito mais derivadas de uma visão de sociedade pragmática, economicista, instrumental, antagônica à visão de Vigotski. Então, no seio da educação ocidental de hoje, há uma incompatibilidade fundamental entre as duas visões. Não vejo possibilidade de se implantarem propostas inovadoras no campo da educação com base nos fundamentos da teoria de Vigotski. Elas podem ser propostas, mas não acredito que sejam implementadas. No Brasil de hoje, menos ainda. Afinal, Vigotski está sendo acusado de pertencer ao marxismo cultural. Considero que a visão que se tem hoje de educação é incompatível com os princípios éticos que fundam uma educação autêntica. Qualquer proposição que visa a uma educação autêntica é incompatível com o que hoje há no mundo. A despeito disso, penso que no seio da família, no ambiente familiar, na vida comum das pessoas, os processos que acontecem estejam muito mais em acordo com a visão histórico-cultural que com qualquer outra. No campo institucional maior, contudo, não vejo qualquer compatibilidade.

Já ouvi críticas afirmando que minha posição é muito radical, pois há muita coisa nova no campo da educação que mostra que houve muitos avanços. Não discordo disso. Houve, de fato, do ponto de vista histórico, muitas mudanças, algumas conquistas importantes. Mudanças, sim. Houve. Mas não transformações. No âmbito das práticas educativas que ocorrem na escola, por exemplo, podemos dizer que muito pouca coisa se transformou. A escola de hoje é muito similar à escola que emergiu no século XII. Não vejo essencialmente grandes diferenças. Evidentemente, se olharmos aspectos mais aparentes, aspectos da superfície, veremos modificações, mas não transformações na essência do que era a educação antes e o que é hoje; uma transformação tal como a que ocorreu entre o período monástico para o do surgimento da escola, aproximadamente no século XII. Talvez, a teoria de Vigotski tenha sido elaborada muito aquém do tempo a que poderia servir; talvez, muitos anos ou séculos antes da sociedade a que poderia servir. Mas isso é pura especulação.

\section{Professora Elizabeth Tunes, como você percebe a apropriação da obra de Vigotski pela academia?}

Vejo que há uma apropriação apenas discursiva, o que, diga-se de passagem, acontece com muitas teorias no campo das ciências humanas e da educação. $\mathrm{Na}$ academia, hoje, a teoria tem servido basicamente para fundamentar um paper. Ela não tem servido para avançarmos em nossas reflexões sobre a realidade que nos cerca. É claro que há muitas pessoas que estudam Vigotski no mundo de hoje e fazem um aporte teórico bastante interessante e profundo, permitindo-nos avançar nesse campo do conhecimento. Lembro-me, por exemplo, das reflexões do professor Angel Pino, da professora Zoia Prestes. Há muitos outros, sem dúvida, não 
somente no Brasil como em todo o mundo: o professor Wladimir Sobkin, Serguei Jerebtsov, estudiosos da própria família de Vigotski, o professor Kravtsov, sua esposa, a professora Elena Kravtsova, o filho Oleg Kravtsov, e muitos outros espalhados pelo mundo. Ainda assim, é um número muito pequeno de pessoas, e certamente não têm o poder de influir no campo da educação a ponto de colaborar para gerar transformações importantes.

Reitero que discursivamente há muita produção, do mesmo modo que, discursivamente, houve muita produção - e ainda há, embora em menor quantidade - de educadores que discorriam sobre a teoria de Piaget. Contudo, quando se examina o interior da escola, efetivamente o que se vê é o que a escola sempre foi. $\mathrm{O}$ discurso que produzimos na academia, de fato, não atinge a prática educativa. O que em geral fazemos é comparecer à escola, observar as relações que lá acontecem, interpretá-las, seja à luz da teoria de Piaget, de Skinner ou de Vigotski, mas efetivamente não inovamos no campo social da educação. Nossos estudos dizem como a escola é sem, contudo, projetá-la para o futuro, sem identificar tendências, sem adiantar-se ao tempo, sem ousadia, como diria Paulo Freire. Que propostas inovadoras no campo da educação a teoria nos autoriza a realizar? No passado, houve quem fizesse isso: Anísio Teixeira, Paulo Freire, Darcy Ribeiro e outros. Hoje, não vejo isso acontecer.

\section{Professora, uma vez que a psicologia, para obter o status de ciências, rom- peu com a filosofia, como você examina o aporte filosófico de Vigotski?}

Eu não diria que a psicologia rompeu totalmente com a filosofia para se tornar ciência. Penso que ela seguiu a tendência majoritária no mundo, à época, apoiando-se no materialismo, como as demais ciências, para propor-se como novo campo científico. Assim, há um fundamento materialista na ciência psicológica; a teoria psicológica não rompeu com a filosofia, portanto. $\mathrm{O}$ que ocorreu foi que alguns teóricos da psicologia afirmaram ter rompido com a filosofia. Piaget, por exemplo, fez isso e é duramente criticado por Vigotski no livro Pensamiento y habla. É impossível a qualquer ciência desvencilhar-se de seus fundamentos filosóficos. Quando se afirma que uma teoria não se ancora em qualquer filosofia, isso já é um fundamento filosófico.

Assim, o que me parece que ocorreu foi que a psicologia rompeu com a metafísica e, ao fazer isso, como várias outras ciências o fizeram, adotou como base um tipo de materialismo, uma corrente filosófica, então hegemônica: o positivismo. Vigotski também adotou o materialismo - o materialismo histórico, que é muito diferente do materialismo calcado no ideário positivista.

\section{Vigotski? \\ Professora Elizabeth, você pode falar um pouco do aporte filosófico de}

Primeiramente, é preciso dizer que, ainda que seja muito conhecido e estudado em todo o mundo, ainda se sabe muito pouco de Vigotski. O que conhecemos dele são seis volumes das chamadas Obras escolbidas e textos esparsos, muitas vezes editados como coletâneas, que foram publicados à época em que ele ainda vivia ou posteriormente, quase que se pode dizer, de maneira semiclandestina, pois 
precisaram ser modificados, alterando certas palavras, cortando certos trechos, em virtude da censura stalinista. A família dele tem trabalhado incansavelmente para conseguir tornar públicos os prováveis dezesseis volumes que comporão sua obra completa. Até o momento, já se publicou, em 2015, o primeiro volume, organizado pelo professor Wladimir Sobkin. Temos informações de que o segundo volume deverá ser publicado proximamente. Vê-se, pois, que dada a extensão de sua obra nós o conhecemos ainda muito pouco.

Sabemos, pelas próprias declarações de Vigotski, que um dos fundamentos de seu pensamento é o materialismo histórico-dialético. Ele afirmou que não trouxe a teoria marxista para fundamentar a psicologia que elaborava num sentido meramente discursivo, o que era comum em sua época entre autores russos. Ele tencionou e realizou a incorporação de princípios marxistas ao seu método, isto é, ao método que elaborava para sustentar a teoria que construía. Vigotski estudou Marx e destilou de sua obra aquilo que seria a base de sustentação e o que estruturaria a psicologia que criava. Não se pode, por isso, afirmar que Vigotski edificou uma psicologia marxista. Essa afirmação não é precisa, pois dá margem a entendimentos dos mais variados acerca do que seria a psicologia de Vigotski. Sabemos, por exemplo, que há ideias de Marx inspiradas em Hegel; nem por isso estamos autorizados a dizer que a filosofia de Marx é hegeliana.

Sabemos que Vigotski mantinha como seu livro de cabeceira o Ética, de Spinoza. Reconhecemos em seus textos, muitas vezes, análises, interpretações e conceituações que estão claramente fundamentadas na visão spinozista. Nos Fundamentos da defectologia, há ideias claramente extraídas do pensamento de Spinoza. Além de Spinoza, temos razões para supor que Vigotski também bebia em fontes filosóficas advindas do judaísmo. O historiador da psicologia Guillermo Blanck foi um dos primeiros a apontar essa possibilidade, demonstrando sua estranheza com a constante negligência em relação às ligações de Vigotski com a questão judaica, o que certamente teria alguma repercussão na constituição do seu pensamento. Segundo Blanck, na cidade em que morava, quando ainda muito jovem, Vigotski vivenciou acontecimentos ligados aos pogroms ${ }^{1}$ que por lá aconteciam, pelo fato de seu pai ser judeu e manter importantes vínculos com a comunidade judaica. E, tão logo comecei a estudar Martin Buber, ${ }^{2}$ percebi muitas semelhanças entre suas ideias e o pensamento de Vigotski. Comecei a investigar se haveria alguma informação indicando uma ligação entre os dois, e de fato Buber esteve em Moscou no início da década de 1920 e mantinha contato com professores e estudantes universitários moscovitas. Conversei sobre isso com a professora Zoia Prestes e, quando fomos à Rússia, em 2007, perguntamos à filha de Vigotski, Guita Lvovna, numa visita que fizemos a ela, sobre a influência da cultura judaica no pensamento de seu pai. Ela negou que houvesse essa influência. Contudo, soubemos mais tarde, por outras fontes, que havia alguma correspondência de Vigotski na qual ele comentava sobre

1 Pogrom é uma palavra russa que significa "causar estragos, destruir violentamente". Historicamente, o termo refere-se aos violentos ataques físicos da população em geral contra os judeus, tanto no império russo como em outros países.

2 Sobre Martin Buber, recomendamos a leitura da obra de Bartholo (2001). 
a questão judaica. Sempre suspeitei de que houvesse alguma aproximação dele com o pensamento hassídico, em virtude até mesmo da sua grande atividade como crítico de teatro, em Gomel. Quando o professor Sobkin esteve em Niterói para participar do VERESK III ${ }^{3}$, realizado em junho de 2016, tive a oportunidade de conversar com ele sobre os indícios da presença do pensamento hassídico na obra de Vigotski. Ele não apenas concordou com essa ideia como também informou que havia informações que subsidiavam essa suspeita. Ele publicara, em 2016, um artigo no qual reproduzia e comentava três textos em que Vigotski mostrava suas impressões e opinião a respeito do comportamento de comunidades de judeus em relação à revolução em curso na Rússia naquela época. Posteriormente, tive a oportunidade de, com Zoia Prestes, traduzir e publicar um artigo de Wladimir Sobkin e Tatiana Klimova ${ }^{4}$. Nesse artigo, os autores comentam sobre a tradução feita por Vigotski para o russo de um conto hassídico escrito em hebraico antigo, entre várias observações sobre a presença do pensamento judaico na vida do $\mathrm{Vi-}$ gotski. Assim, a tradução desse conto hassídico mostra-nos que Vigotski era um leitor de contos hassídicos. Creio que seja possível afirmar que, assim como Buber (2004), que elabora uma filosofia antropológica, Vigotski também criou uma espécie de "psicologia antropológica" que, tudo leva a crer, assenta-se no pensamento de Spinoza e no pensamento hassídico também, além de ancorar-se no materialismo histórico-dialético de Marx. Trata-se, pois, de uma psicologia própria do ser humano, com fortes fundamentos numa filosofia antropológica. Apenas a título de exemplo, isso implica uma noção de desenvolvimento muito específica, muito particular, que não é encontrada, que eu saiba, em nenhuma teoria psicológica de desenvolvimento conhecida. Considero essa uma das noções mais complexas da obra de Vigotski, que não descarta, do ponto de vista ético, a própria responsabilidade da pessoa que se desenvolve. Esse é um ponto muito importante, que aproxima bastante Vigotski e Paulo Freire. O professor Guenadi Kravtsov (2014) discute o conceito de desenvolvimento em Vigotski. Um de seus textos encontra-se publicado na revista Veresk, sediada no repositório do Centro Universitário de Brasília. São esses, pois, alguns dos fundamentos que reconheço na obra de Vigotski, considerando-se o que dela eu conheço. Acho interessante também destacar outro exemplo. No livro em que Vigotski empreende um estudo das emoções, é possível verificar, pelas críticas que tece a William James e a outros teóricos no campo das emoções e no próprio campo da arte, esses fundamentos ético-filosóficos de sua teoria.

\section{Professora, como você analisa as ideias de Vigotski no cenário da socie- dade atual?}

É muito penoso e difícil pensar sobre isso. Difícil porque considero que estamos em uma fase em que vivemos uma transformação cultural, uma revolução cultural. Estamos deixando para trás uma sociedade cujo centro cultural era o texto

3 Simpósio Brasileiro Russo da Teoria Histórico Cultural: História e Atualidade.

4 A saber: "Vigotski desconhecido: a experiência de tradução literária do hebraico antigo", em Teoria e Prática da Educação, v. 22, n. 1, p. 3-24, jan./abr. 2019. 
livresco e adentrando em uma sociedade em que esse centro cultural é a imagem técnica. Isso tem implicações graves para a nossa vida e para a psicologia, de um modo geral. Certamente, precisaremos reconstruir a teoria psicológica, pois estamos diante da emergência de um novo homem. Toda revolução cultural cria um novo homem, e, em decorrência, há a necessidade de uma nova psicologia. Penso que as novas teorias sobre o homem que está a emergir começarão a surgir a partir de agora. Não sei e não tenho como afirmar como ficará a teoria de Vigotski. Acho difícil acreditar que ela dará conta desse novo homem. Certamente, surgirão novas teorias psicológicas, se é que se pode chamar assim o conhecimento que virá; não sei que rumos tomaremos; não sei o que será a ciência daqui em diante. Ela também se transformará. Flusser (2008) aponta algumas perspectivas a respeito desse futuro. Ele nos ajuda a refletir sobre elas. A teoria de Vigotski é válida para compreendermos a realidade que temos até aqui. Creio, contudo, que haverá uma grande transformação na esfera da ciência, das artes, enfim, dos afazeres humanos, de um modo geral. Está nascendo uma nova cultura e com ela um novo pensamento humano. Mas ainda é difícil saber qual é essa cultura e qual é esse novo modo de pensamento. Estamos no ocaso de uma era, com toda a nostalgia ou melancolia que isso pode gerar, uma melancolia própria da expectativa de destruição do mundo velho, digamos assim. Sabemos que um novo mundo está a emergir, embora isso não atenue nossa melancolia por não sabermos o que está para nascer. As ideias de Vigotski nunca morrerão, porque nenhuma grande obra deixa de existir. As obras de arte, as grandes obras científicas, as grandes teorias científicas, as grandes teorias filosóficas nunca morrem. São legados que a humanidade carrega consigo quase como se fossem eternos. Não morrem e tornam-se fundamentos para novas possibilidades que emergem, atualizam-se em novas formas.

Comecei dizendo penoso e difícil. Falei primeiramente do difícil. Encerro com o penoso. No Brasil dessa triste era que se inaugurou em meados de 2016, é penoso falar do cenário atual porque é melancólico ver nossa sociedade mergulhar no abismo do império fascista.

\section{Professora Elizabeth, você gostaria de destacar algum conceito que en- tende ser muito relevante para estudar os postulados teóricos de Vigotski?}

Vigotski construiu um sistema muito bem articulado de conceitos. Se extrairmos desse sistema um dos conceitos para elegê-lo como o mais relevante ou outro qualificativo qualquer, ele perde os elos com os demais e fica enfraquecido. Todo sistema teórico é uma constelação de conceitos e cada conceito somente encontra seu lugar e seu brilho se situado nessa constelação, em uma relação muito bem arranjada, lógica e esteticamente, com os demais. Penso que o mais interessante quando estudamos uma teoria, principalmente uma teoria da grandeza que tem a de Vigotski, não é importante ir atrás do modo como ela responde a questões sobre o mundo, mas quanto ela nos permite refletir sobre esse mundo e formular novas inquirições. Acho que eu sintetizaria assim: Tanto mais fértil é uma teoria quanto mais ela nos dá acesso a dúvidas. São as dúvidas que nos movem e nos possibilitam viver. As certezas são paralisantes e, por isso, são a morte do pensamento. 
Penso que a teoria de Vigotski é um ponto de partida para indagações que certamente faremos a respeito da nova cultura emergente. Então, por exemplo: se, nessa era que se encerra, o nosso espaço mental constituía-se fundamentalmente pela relação entre pensamento e palavra, como podemos pensar tendências novas nessa cultura emergente em que essa relação agora será também e, talvez, principalmente mediada pela imagem técnica? Com base no que Vigotski teorizou a respeito da relação entre pensamento e fala e em seus estudos sobre imaginação, o que podemos projetar para o novo mundo que está a surgir? Na verdade, toda teoria serve a esse mister: instrumentar-nos para que possamos criar dúvidas e projetar novas tendências. A possibilidade de dúvidas fomentadas por uma teoria é a garantia da persistência desta. Este é, para mim, o aspecto mais importante do sistema teórico de Vigotski: a sua potência para gerar questões. É por isso que ele é revolucionário e genial.

\section{CONSIDERAÇÕES FINAIS}

Agradecemos a oportunidade de entrevistar a professora doutora Elizabeth Tunes e destacamos a relevância da contribuição de seus estudos para a psicologia e para a educação, com sua investigação a respeito dos princípios filosóficos, em que Vigotski postula suas ideias, possibilitando o entendimento do sistema conceitual de sua teoria.

Falar da teoria histórico-cultural de Vigotski e suas implicações no contexto atual em que o Brasil se encontra é falar de algo totalmente paradoxal às nossas políticas públicas para a educação e ao projeto de sociedade que se acha em construção. Ao longo dos anos, os escritos de Vigotski foram frequentemente deturpados, corroborando conceitos divergentes à sua teoria. Ao considerarmos suas proposições, verificamos que elas não convergem com as perspectivas de educação vigente nas sociedades contemporâneas. As ideias de Vigotski apontam para uma educação autêntica, em que os indivíduos se relacionem dialogicamente na coletividade.

\section{ALGUMAS OBRAS DA PROFESSORA DOUTORA ELIZABETH TUNES PERTINENTES À TEMÁTICA}

PRESTES, Z. R.; TUNES, E. Lev Vigotski, a Revolução de Outubro e a questão judaica: o nascimento da teoria histórico-cultural no contexto revolucionário. Fractal, v. 29, n. 3, p. 288-290, 2017. https://doi.org/10.22409/1984-0292/v29i3/2597

TUNES, E. Estudos sobre a teoria histórico-cultural e suas implicações educacionais. Fractal, v. 27, n. 1, p. 7-11, 2015. https://doi.org/10.1590/1984-0292/1337

TUNES, E. A defectologia de Vigotski: uma contribuição inédita e revolucionária no campo da educação e da psicologia. In: KRAVTSOVA, E.E. (orgs.). VERESK: Estudos sobre a perspectiva histórico-cultural de Vigotski. Brasília: UNICEUB, 2017. v. 1. p. 75-84. 
VIGOTSKI, L. S. 7 aulas de L. S. Vigotski sobre os fundamentos da pedologia. Tradução e organização de Zoia Prestes e Elizabeth Tunes. Rio de Janeiro: E-papers, 2018a.

VIGOTSKI, L. S. Imaginação e criação na infância. Tradução de Zoia Prestes e Elizabeth Tunes. São Paulo: Expressão Popular, 2018b.

\section{REFERÊNCIAS}

BUBER, M. Eu e tu. São Paulo: Centauro, 2004.

FLUSSER, V. O universo das imagens técnicas: elogio da superficialidade. São Paulo: Annablume, 2008.

KRAVTSOV, G. As bases filosóficas da psicologia histórico-cultural. In:JEREBTSOV, S. et al.VERESK: Cadernos Acadêmicos Internacionais. Estudos sobre a perspectiva histórico-cultural de Vigotski. Brasília: UNICEUB, 2014. p. 29-42.

SKINNER, B. F. Verbal Behavior. Acton: Copley, 1957.

VIGOTSKI, L. S. Pensamento e Linguagem. São Paulo: Martins Fontes, 1991.

VIGOTSKI, L. S. Pensamiento y habla. Tradução de Alejandro Ariel González. Buenos Aires: Colihue, 2007.

VYGOTSKY, L. S. Thought and Language. Cambridge: The MIT Press, 1986.

VYGOTSKI, L. S. Fundamentos de defectología. Madri: Visor, 1997. (Obras Escogidas, v. 5).

\section{SOBRE AS AUTORAS}

IngRID LiLian Fuhr é doutora em educação pela Universidade de Brasília (UnB). Professora do Centro Universitário de Brasília (UniCEUB).

E-mail: ingridlfra@gmail.com

Darliane Silva do Amaral é doutora em educação pela Universidade de Brasília (UnB).

E-mail: darliane.amaral@gmail.com

Aline de Souza Pereira é doutoranda em educação pela Universidade de Brasília (UnB). Orientadora educacional da Secretaria de Educação do Distrito Federal (SEEDF).

E-mail: souzapaline1@gmail.com

Recebido em 6 de julho de 2020

Aprovado em 4 de novembro de 2020 